\title{
Erratum to: The Handbook of Formal Methods in Human-Computer Interaction
}

\author{
Benjamin Weyers, Judy Bowen, Alan Dix and Philippe Palanque
}

\section{Erratum to:}

\section{B. Weyers et al. (eds.), The Handbook of Formal Methods in Human-Computer Interaction, Human-Computer Interaction Series, DOI 10.1007/978-3-319-51838-1}

The original version of the book was inadvertently published without the following corrections:

In Chapter 2, S. Van Mierlo (e-mail: simon.vanmierlo@uantwerpen.be), Y. Van Tendeloo (e-mail: yentl.vantendeloo@uantwerpen.be), Y. Van Tendeloo, B. Meyers (e-mail: bart.meyers@uantwerpen.be), and H. Vangheluwe (e-mail: hv@cs.mcgill. ca) have to be changed to read as J. Bowen (e-mail: jbowen@waikato.ac.nz), A. Dix (e-mail: alanjohndix@gmail.com), A. Dix, P. Palanque (e-mail: palanque@irit.fr), and B. Weyers (e-mail: weyers@vr.rwth-aachen.de), respectively.

In Chapter 5, S. Van Mierlo (e-mail: simon.vanmierlo@uantwerpen.be) has to be changed to read as B. Weyers (e-mail: weyers@vr.rwth-aachen.de).

In Chapter 6, S. Van Mierlo and Y. Van Tendeloo (e-mail: simon.vanmierlo@uantwerpen.be) has to be changed to read as J. Bowen and S. Reeves (e-mail: jbowen@waikato.ac.nz); Y. Van Tendeloo (e-mail: yentl.vantendeloo@uantwerpen. be) has to be changed to read as S.Reeves (e-mail: stever@waikato.ac.nz).

The updated online version for this book can be found at

DOI 10.1007/978-3-319-51838-1_2,

DOI 10.1007/978-3-319-51838-1_5,

DOI 10.1007/978-3-319-51838-1_6,

DOI 10.1007/978-3-319-51838-1_8,

DOI 10.1007/978-3-319-51838-1_10,

DOI 10.1007/978-3-319-51838-1_11,

DOI 10.1007/978-3-319-51838-1_12,

DOI 10.1007/978-3-319-51838-1_13,

DOI 10.1007/978-3-319-51838-1_14,

DOI 10.1007/978-3-319-51838-1_15 and DOI 10.1007/978-3-319-51838-1_16 
In Chapter 8, S. Van Mierlo and Y. Van Tendeloo (e-mail: simon.vanmierlo@uantwerpen.be) has to be changed to read as P. Curzon and R. Rukšènas (e-mail: p.curzon@qmul.ac.uk); Y. Van Tendeloo (e-mail: yentl.vantendeloo@uantwerpen.be) has to be changed to read as R. Rukšènas (e-mail: r.ruksenas@qmul.ac.uk).

In Chapter 10, S. Van Mierlo (e-mail: simon.vanmierlo@uantwerpen.be) has to be changed to read as B. Weyers (e-mail: weyers@vr.rwth-aachen.de).

In Chapter 11, S. Van Mierlo and Y. Van Tendeloo (e-mail: simon.vanmierlo@uantwerpen.be) has to be changed to read as G. Maudoux and C. Pecheur (e-mail: guillaume.maudoux@uclouvain.be); Y. Van Tendeloo (e-mail: yentl.vantendeloo@uantwerpen.be) and B. Meyers (e-mail: bart.meyers@uantwerpen.be) have to be changed to read as C. Pecheur (e-mail: charles.pecheur@uclouvain.be) and S. Combéfis (e-mail: s.combefis@ecam.be), respectively.

In Chapter 12, S. Van Mierlo and Y. Van Tendeloo (e-mail: simon.vanmierlo@uantwerpen.be) has to be changed to read as J. Bowen and A. Hinze (e-mail: jbowen@waikato.ac.nz); Y. Van Tendeloo (e-mail: yentl.vantendeloo@uantwerpen.be) has to be changed to read as A. Hinze (e-mail: hinze@waikato.ac.nz).

In Chapter 13, S. Van Mierlo (e-mail: simon.vanmierlo@uantwerpen.be) and Y. Van Tendeloo (e-mail: yentl.vantendeloo@uantwerpen.be) have to be changed to read as M.L. Bolton (e-mail: mbolton@buffalo.edu) and E.J. Bass (e-mail: ejb96@drexel.edu), respectively.

In Chapter 14, S. Van Mierlo (e-mail: simon.vanmierlo@uantwerpen.be) has to be changed to read as M.D. Harrison (e-mail: michael.harrison@ncl.ac.uk); Y. Van Tendeloo and B. Meyers (e-mail: yentl.vantendeloo@uantwerpen.be) has to be changed to read as P.M. Masci and J.C. Campos (e-mail: paolo.masci@inesctec.pt); B. Meyers (e-mail: bart.meyers@uantwerpen.be) and H. Vangheluwe (e-mail: hv@cs.mcgill.ca) have to be changed to read as J.C. Campos (e-mail: jose.campos@di.uminho.pt) and P. Curzon (e-mail: p.curzon@qmul.ac.uk), respectively.

In Chapter 15, S. Van Mierlo , B. Meyers, and N. Rungta (e-mail: simon.vanmierlo@uantwerpen.be) has to be changed to read as G. Brat , D. Giannakopoulou, and N. Rungta (e-mail: Guillaume.P.Brat@nasa.gov); B. Meyers (e-mail: bart.meyers@uantwerpen.be), N. Rungta (e-mail: Neha.S.Rungta@nasa.gov), Y. Van Tendeloo (e-mail: yentl.vantendeloo@uantwerpen.be), H. Vangheluwe (e-mail: hv@cs.mcgill.ca), and F. Raimondi (e-mail: f.raimondi@mdx.ac.uk) have to be changed to read as D. Giannakopoulou (e-mail: Dimitra.Giannakopoulou@ nasa.gov), N. Rungta (e-mail: Neha.S.Rungta@nasa.gov), S. Combéfis (e-mail: sebastien.combefis@uclouvain.be; s.combefis@ecam.be), C. Pecheur (e-mail: charles.pecheur@uclouvain.be), and F. Raimondi (e-mail: f.raimondi@mdx.ac.uk), respectively.

In Chapter 16, G. Brat, S. Combéfis, and D. Giannakopoulou (e-mail: Guillaume.P.Brat@nasa.gov) has to be changed to read as S. Van Mierlo, Y. Van Tendeloo, and B. Meyers (e-mail: simon.vanmierlo@uantwerpen.be); S. Combéfis (e-mail: sebastien.combefis@uclouvain.be; s.combefis@ecam.be), D. Giannakopoulou (e-mail: Dimitra.Giannakopoulou@nasa.gov), C. Pecheur (e-mail: 
charles.pecheur@uclouvain.be), and C. Pecheur have to be changed to read as Y. Van Tendeloo (e-mail: yentl.vantendeloo@uantwerpen.be), B. Meyers (e-mail: bart.meyers@uantwerpen.be),H. Vangheluwe (e-mail: hv@cs.mcgill.ca), and H. Vangheluwe, respectively.

The erratum book has been updated with the changes. 